\title{
Research Paper: The Effect of Low Friction in Pavement Due to Floods and High-speed Vehicles in Increasing the Number of Rescue Vehicles' Driving Accidents
}

\author{
Mohammad Mehdi Khabiri $^{1^{*}}$ (D), Zohrah Ghaforifard ${ }^{1}$ (D) \\ 1. Department of Civil Engineering, School of Engineering and Technolgy, Yazd University, Yazd, Iran.
}

Citation Khabiri MM, Ghaforifard Z. The Effect of Low Friction in Pavement Due to Floods and High-speed Vehicles in Increasing the Number of Rescue Vehicles' Driving Accidents. Health in Emergencies and Disasters Quarterly. 2020; 6(1):29-38. http:// dx.doi.org/10.32598/hdq.6.1.233.2

http://dx.doi.org/10.32598/hdq.6.1.233.2

Article info:

Received: 11 Jun 2020

Accepted: 02 Sep 2020

Available Online: 01 Oct 2020

\section{Keywords:}

Road safety, Injury, Health services, Car accidents, Emergency, Flooded pavement

\begin{abstract}
A B S T RACT
Background: The rescue operation is dangerous during floods when the street surface is wet and the rescue vehicles moving fast. Rural roads are known with a high percentage of run-offthe-road crashes and accidents, mostly affected by the unsuitable and inappropriate speed of the car and failure to keep a safe side distance from the highway alignment. Determining the length of the vertical curve and the stopping distance depends on the speed parameter in the geometric design. This parameter depends on the traffic flow and the vehicle driver.

Materials and Methods: The calculation of distance visibility, especially in the vertical and horizontal curves, has a significant role in the geometric design of roads and the safety of roads and drivers. This study investigates changes in two critical parameters of friction surface of pavement and vehicles' speed on the probability of accidents. In the present study, by changing the speed parameter, namely, increasing speed and decreasing friction, and reducing the distance of vision, the required vertical curve is calculated and compared with the existing curve length. Thus, when the curve length does not match the required arch length, the accident's probability increases.

Results: One of the study's findings indicates that with a 5\% decrease in the friction coefficient of the vertical curve, the probability of accident increases by about $20 \%$. The results show that an approximately $10 \%$ increase in speed can raise the likelihood of a crash by $25 \%$ on average.

Conclusion: The use of accident reduction-related strategies for rescue vehicles and ambulances will help the victims affected by natural disasters. The results showed that choosing the right speed is very important in flooded wet streets. Driving fast to speed up the relief operation not only increases the risk of traffic accidents but also slows down the relief of natural disasters. The results indicate the proper performance of the model created by the probabilistic method. Besides, this model's use has the advantage of correctly identifying the factors affecting the increase in risk. Also, it helps to take the right measures to increase safety in the relief of natural disasters, especially floods.
\end{abstract}

\section{* Corresponding Author:




\section{Introduction}

ecause of the complexity of urban environments, flood risk in urban areas has increased in recent years compared to B non-urban areas. It is always the concern of decision-makers and public and urban health managers. Floods in urban areas have caused extensive damage to buildings and other urban infrastructures and slowed down traffic systems. The risk of flooded streets and skid resistance reduction are two major safety concerns in wet weathering movement operations on roads. Hydroplaning on wet pavement occurs when a rescue vehicle reaches a critical speed and lost contact of its tires with the pavement surface. The harshness of the motorization also creates some adverse consequences on persons and the environment. The most adverse factors are related to traffic crashes and loosening travel safety regulations [1]. The highway geometric design seeks to provide the maximum traffic safety for vehicles. Highway geometric design is based on the speed of the cars. Possibly, the vehicle speed is not based on the speed limit or the designed speed in some parts of the highway. The length of crest vertical curves is determined based on the design speed. If a vehicle drives faster than the speed limit, the probability of a crash will exist, especially while driving in two-lane roadways. At the beginning of the present paper, the focus is on the importance and role of speed in a geometric design.

Highway geometric conditions should provide traffic safety and efficiency. Design speed affects geometric factors like the minimum radius of the horizontal curve, superelevation, or length of the vertical curve. Maybe, the drivers do not follow the design speed in different routes speed, which is introduced as operating speed. Vehicles' movement by this speed can be a driving violation and create some dangers for drivers. One of the essential points in two-lane roadways design is to provide the possibility of free passing. As the rate of road length with the possibility of passing increases, its safety and capacity increase too $[2,3]$.

It is necessary to clarify the relationship between traffic accidents, geometric condition, and road specification to prevent driving accidents and provide a comfortable and safe driving environment. An important topic in reducing the number of traffic accidents is to identify and analyze the influential factors. Determining the safety level of the highway segment is the significant role of models for predicting accidents. Therefore, Park et al. and Khabiri et al. have presented the relationship between determined variables and the accident frequency in their research to increase the safety of the study area $[4,5]$. Accidents for rescue vehicles not only damage people but also increase traffic congestion, slow down transportation, and hunks the infrastructures. Traffic injuries for expectable and avoidable events are among the most significant public health challenges [6].

In their research about increasing speed limits in rural highways, Renski and colleagues reported that if the speed limit increases from $88.5 \mathrm{~km} / \mathrm{h}$ to $96.5 \mathrm{~km} / \mathrm{h}$ or from $88.5 \mathrm{~km} / \mathrm{h}$ to $104.5 \mathrm{~km} / \mathrm{h}$, the probability of sustaining minor and non-in-capacitating injuries increases, too. But when the speed increases from $104.5 \mathrm{~km} / \mathrm{h}$ to $112.5 \mathrm{~km} / \mathrm{h}$, crash severity did not increase significantly [7]. The main goal of Moomen's thesis was to present the predicting models of the impact of geometric conditions, traffic volumes, and speed on truck-related crashes in two-lane roadways. He used a negative binomial regression model for indicating this relationship [8]. For considering the importance of two-lane roads, we can refer to Chang et al. research result [9]. The results show that $85 \%$ of rural highways are in two-lane roadways, and approximately $80 \%$ of paved highways are two-lane roads, and $40 \%$ of fatal crashes occurred on these highways. According to National Highway Traffic Safety Administration (NHTSA), about $30 \%$ of the deadly accidents are the result of high speed. Then, there is a significant relationship between crash rates, mean velocity, and traffic variability [7].

The calculated length of vertical curves based on passing sight distance is more than the length of vertical curves based on stopping sight distance, and so it needs to more earthwork volume. As the length of road with free passing increases in two-lane roadways, the road capacity increases in the same ratio too. When the length of the free passing road is $20 \%$, the Volume per Capacity (V/C) factor will be 0.85 , and when the whole road has free passing, this factor will be 0.75 [9]. By Increase in the possibility of passing in crest vertical curve zones, a crash likelihood may increase because of the length limitation on curves. Also, a crash likelihood may increase because of the length limitation on curves. There was no research about the effect of speed increase on the possibility of a collision in vertical curves. But in the present study, we tried to examine this parameter $[10,11]$. The scientific sources, while pointing out the importance of transport safety issues, refer to many models developed to predict crashes for providing reduced accident solutions [11, 12]. When the roughness and friction of the road surface reduce, the accident rate increases. The rate of accidents at wet surfaces in the curves is the highest. Also, crashes at 
uphill and downhill wetlands (over 3\%) are higher than incident rates in flat parts of the road. Reducing the skid resistance at the surface of rugged roads and wet pavement can be problematic and dangerous due to the lack of control of heavy vehicles in the curve of the vertical axis $[12,13]$. For the height visibility parameter of drivers in design relationships, different countries have used other numbers for the geometric design of their roads.

In a field survey, Mavromatis et al. tried to localize these figures and provide a suitable equation for calculating the convex vertical arc length use in the geometric design of the roads of the country [14]. Aboutalebi Esfahani, M. and Hojjati in a study attempted to introduce a new interface for vertical curves, which, in addition to mitigating the existing curves, would solve the problem of the sudden arrival of the acceleration from the center in such a way that the vertical arc can only be verified by the conditions defined by a relationship [14, 15]. Application is an essential step in the preparation and implementation of disaster risk plans. Therefore, the real conditions related to rescue in critical situations must be carefully examined [13]. Dong et al. have used data related to driving events in Indiana for making statistical and stochastic models in research. This model represented driving event intensity as a function of highway geometric design factors [16]. Easa presented another new method for calculating the length of vertical curves in further research and based on this design method, we could increase safety, especially in asymmetrical vertical curves [17]. The purpose of referring to these two research studies is to determine that speed, especially in vertical curves, can decrease driving incident intensity. Easa and Atif did another research about Operating Speed (OS) for designing the two-lane rural highways. This research suggested that highway geometric alignment design can be done based on a model for the anticipation of operating speed. The results show that design speed and operating speeds have differences, and it is necessary to do more studies about control of driving events and schedule for its reduction [18].

Aarts and Van Schagen have presented a formula or calculation of relative risk based on the traffic speed and then presented a determined exponential model. According to this model, when the vehicle speed is 10 $\mathrm{km} / \mathrm{h}$ more than the average speed, the risk of a crash increases 2.2 times [19]. Hong and Oguchi examined the effect of geometric design on operating speed in Japan. The research findings verified that steep uphill in vertical curves affects the operating speed on a dry surface, and this relation is nonlinear [8].
In this study, to improve the level of curve safety, the effect of the change in the longitudinal slope of the path leading to the vertical curve based on the stopping distance was considered. The study investigates the possibility of accidents for relief vehicles by considering wet pavement and reducing friction in floods.

\section{Materials and Methods}

In selecting the length of the crest, vertical curves are examined for determining passing sight distance. The existing length of crest vertical, the curves, and the required length of curves are compared with respect to changes in vehicle speed. Thus, the probability of a crash is anticipated. Also, the effect of violation in excessive speed and low speed is considered using the statistics hypothesis. Specifically, in the vertical and horizontal curves, computing sight distances have always had a significant role in the geometric design of roads and the safety of roads and drivers. Over the years, this fact has always been accompanied by various changes and developments and studied by experts in the field. The effect of the friction of the pavement is defined by the "skid number" parameter, which depends on the speed of the vehicles and the wet pavement in flood conditions. Due to the polishing of the aggregates, this number has decreased and required stop sight distance increase, resulting in car accidents.

The development of road design methods has led to various assumptions about input variables and design conditions. Different methods can estimate the error resulting from these assumptions. With the view of risk investigation, we studied the design of the vertical curve. The calculation of the length of vertical curves is an essential parameter in vertical curve design, which is considered in highway geometric design manual in different countries. In a published manual by the Iowa Department of Transportation Office of Design, Equations 1-3 are used to calculate the length of the vertical curve based on passing sight distance [3].
1. $L=K \times A$
2. $L=\frac{A \times S^{2}}{864}$ If $\quad S<L$
3. $L=2 \times S-\frac{864}{A}$ If $\quad S\rangle L$

, where:

$\mathrm{S}=$ Stopping distance $(\mathrm{m})$

$\mathrm{L}=$ Length of vertical curves $(\mathrm{m})$ 
$\mathrm{A}=$ Algebraic difference in grades $(\%)$

$\mathrm{K}=$ Measure of curvature, it is obtained from existing tables in geometries design manuals.

In a study, Lord and Bonneson used AMF (Accident Modification Factor) to determine the effect of roadway geometric specification on the numbers of a road crash. This factor is used to indicate the impact of the safety of a geometric design factor or traffic control condition, and they presented a formula for calculation of AMF for curves and at grade intersection in their study [20]. In another research work, the travel accidents were studied from 3 different categories of viewpoint [21]:

1- Micro viewpoint;

2- Medium viewpoint;

3- Macro viewpoint.

Roadway safety may be ensured by regular operation of all system components, including the driver, vehicle, and transportation intermediate system [22]. In this research, we assumed that the speed of the car was irregular, and the geometry of the road is not adequate. This study evaluates highway safety with the medium viewpoint. It attempts to assess the effect of road geometry parameters and vehicle speed on the number of traffic accidents and calculate the probability of traffic accidents considering the above factors.

The Effect on the Rate change of grade on Length of Vertical Curve

In calculating the length of the crest, vertical curves are used from the rate of change of grade parameter (A). For a determined design speed, the amount of " $\mathrm{K}$ " in Equation 4 is fixed, but the amount of " $\mathrm{A}$ " depends on the algebraic difference between grades of two tangents in two sides of curves $[3,22]$.

$$
\text { 4. } A=\left|G_{2}-G_{1}\right|
$$

, where:

$\mathrm{A}=$ Algebraic difference between grades.

When the vehicle is on a steep path, the driver is in trouble with the vehicle's control, and to stop or control a vehicle, more friction is required. Therefore, the effect of slip resistance on arc length is of particular importance. In a published manual, Equation 5 was used to calculate the length of stop sight distance [3].
5. $D S D=0.2788 . V . t+0.39 \frac{v^{2}}{\left(f \pm G_{i}\right)}$

, where:

$\mathrm{t}=$ Time of vision and reaction (s),

$\mathrm{Gi}=$ The longitudinal slope $(\%)$

$\mathrm{v}=$ Speed of vehicles $(\mathrm{km} / \mathrm{h})$

$\mathrm{f}=$ Surface friction $(\%)$,

$\mathrm{DSD}=\mathrm{S}=$ Stop sight distance $(\mathrm{m})$.

It should be noted that changing the slope value alters the stop sight distance. If the friction decreases, the required stop sight distance is added. Besides, the weight of heavy vehicles is also notable. In the next step, by reducing the degree of friction, the length of the stop sight distance increases and is used in the calculation of the vertical curve length.

\section{Results}

In this section, a summary of the results and their analyses are presented in three parts. After reviewing and analyzing all the data, each variable on the risk of traffic accidents in crisis management conditions is examined.

\section{Change in the length of vertical curve}

The changes in design speed lead to changes in the needed length of the vertical curve. To test the effect of changes in the amount of " $\mathrm{A}$ " in the length of the crest, vertical curves are drawn for three speeds of 70,90, and $110 \mathrm{~km} / \mathrm{h}$ (Figure 1).

By considering the diagram, in higher speed, the effect of parameter " $\mathrm{A}$ " is greater in calculating the length of crest vertical curves.

Figure 2 shows the change in lengths of the vertical curve as a result of changes in speed. As it is presented in Figure 2, if drivers of ambulances and rescue vehicles increase their speed from $60 \mathrm{~km} / \mathrm{h}$ to $70 \mathrm{~km} / \mathrm{h}$, the length of the vertical curve should increase $35 \mathrm{~m}$; but by increasing speed from $90 \mathrm{~km} / \mathrm{h}$ to $100 \mathrm{~km} / \mathrm{h}$, the length of the curve should increase about $105 \mathrm{~m}$. Generally, in speeds slower than $90 \mathrm{~km} / \mathrm{h}$, by each $10 \mathrm{~km} / \mathrm{h}$ increase in speed, the length of the horizontal curve increases $60 \mathrm{~m}$ on the average, and in speeds over $90 \mathrm{~km} / \mathrm{h}$, this amount will be $130 \mathrm{~m}$. By considering this matter, increasing the 


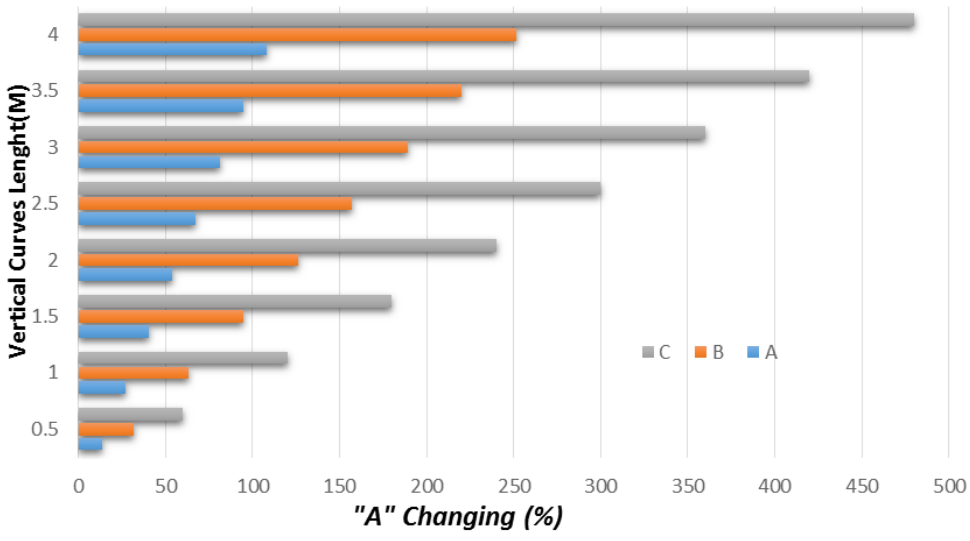

ealth in

Figure 1. The diagram of changes in the length of crest vertical curves $(\mathrm{m})$ due to changes in parameter " $\mathrm{A}$ " and speeds $(\mathrm{km} / \mathrm{h})$ : $\mathrm{a}-70 ; \mathrm{b}-90 ; \mathrm{c}-110$

probability of an accident in speed over $90 \mathrm{~km} / \mathrm{h}$ will be greater because of the length of the vertical curve.

\section{The effect of wet pavement and high speed}

Dangerous passing in crest vertical curves begins from steep uphill of the curve, where the sight is limited, and it ends on the downhill of the curve. Operating speed in steep uphill of vertical curves is between $95 \mathrm{~km} / \mathrm{h}$ and $120 \mathrm{~km} / \mathrm{h}$ in grade zone $0 \%$ to $2 \%$. The diagram about operating speed in different grades, which is the result of research done by Hong and Oguchi in Japan, is shown in Figure 3 [8]. Therefore, selecting the length of the suitable vertical curve, especially for speeds over $90 \mathrm{~km} / \mathrm{h}$ and by grade lower than $2 \%$, is very important.

The stop sight distance was calculated by Equation 5 to determine the effect of friction, change on the sight stopping distance, and subsequently, on the length of the vertical curve, on different slopes, and at different speeds.
The number of friction was chosen according to the speed (0.76 to 0.7 ). Thus, the friction number decreased, and according to different slopes from 0 to \pm 7 , the sight stopping distance between tow was calculated. The friction number is dependent on vehicle speed and surface pavement moisture in runoff (Figure 4). As friction decreases, the need for a more sight stopping distance is required because in the vertical curve, the curve length is constant, the probability of accidents increases to the same scale.

\section{Risk of accident in crest vertical curves}

Where passing is free, if a driver in crest vertical curve passes by a speed higher than the designed speed, he needs more length of curve that perhaps this free length is not available. For example, the design speed and speed limit is $80 \mathrm{~km} / \mathrm{h}$ in the vertical curve, and the existing length of it for $\mathrm{A}$ as $2 \%$ is $85 \mathrm{~m}$. A violent or high-speed rescue vehicle driver by the speed of $90 \mathrm{~km} / \mathrm{h}$, to pass

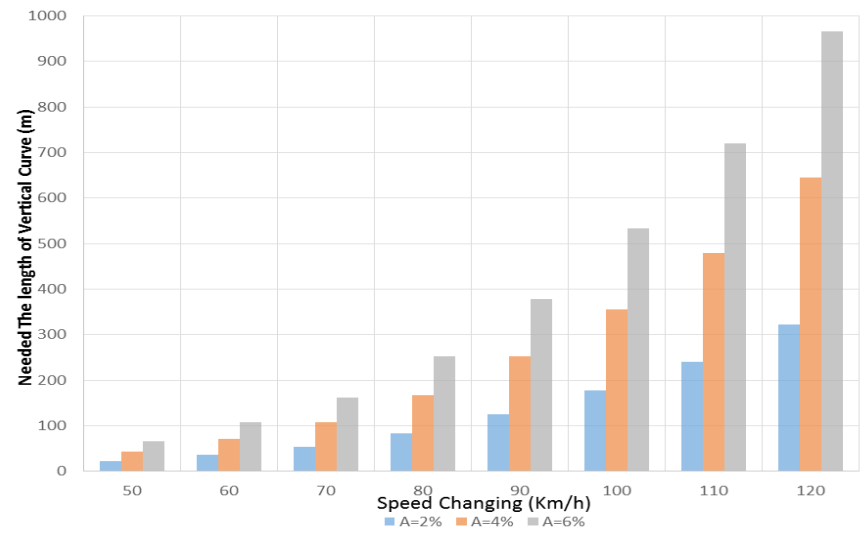

Figure 2 Effect of changes in the required length of the vertical curve based on speed changes for different " $\mathrm{A}$ " parameter 


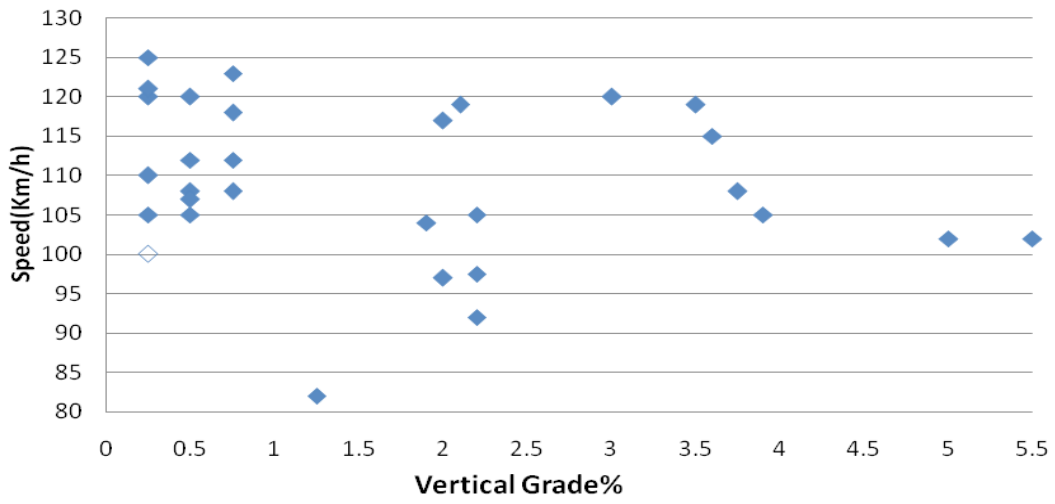

Figure 3. Diagram of change in speeds in different vertical grades

this curve, needs a curve length of about $125 \mathrm{~m}$. It means a distance around $200 \mathrm{~m}$ is not seen in the crest vertical curve for a driver. Therefore, the probability of crash can be determined by the following relation (Equation 6):

6. $P_{A}=\frac{\left(L_{N}-L_{E}\right)}{L_{N}} \times 100$

, where:

$\mathrm{PA}=$ risk of accident (in percent),

$\mathrm{LN}=$ The required length of the vertical curve considering the vehicle speed while passing $(\mathrm{m})$;

$\mathrm{LE}=$ The existing length of the vertical curve considering design speed (m).

In this example, by increasing $10 \mathrm{~km} / \mathrm{h}$ in speed, the probability of a crash increased $30 \%$. It uses parameter " $A$ " to calculate the likelihood of a collision, and this parameter changes increasingly to determine the effect of changes in speed. Then, the required length of the vertical curve and increasing the probability of crash can be calculated at any speed. Table 1 presents the calculation related to the likelihood of crash for speeds of $70 \mathrm{~km} / \mathrm{h}, 90 \mathrm{~km} / \mathrm{h}$, and $110 \mathrm{~km} / \mathrm{h}$, and " $\mathrm{A}$ " is considered $4 \%$. Figure 5 represents a comparison between the probabilities of a crash in different design speeds due to an increase in speed from $0 \%$ to $10 \%$.

\section{Discussion}

Decision tree pattern of rescue vehicles' driving accidents risk

Data mining and data clustering apparatuses, as powerful engineering tools, causes complex analysis time and high-cost decrement. Decision Tree Construction (DTC) is a classic method for classification and arrangement. The decision tree was modeled using SPSS for records, and Figure 6 was formerly obtained. This diagram has got 4 branches and 6 leaves. The accident risk is dependent on the increased speed in the second branch. If the rescue vehicle speed passes $93.5 \mathrm{~km} / \mathrm{h}$, accidents risk dramatically decreases. Though, statisti-

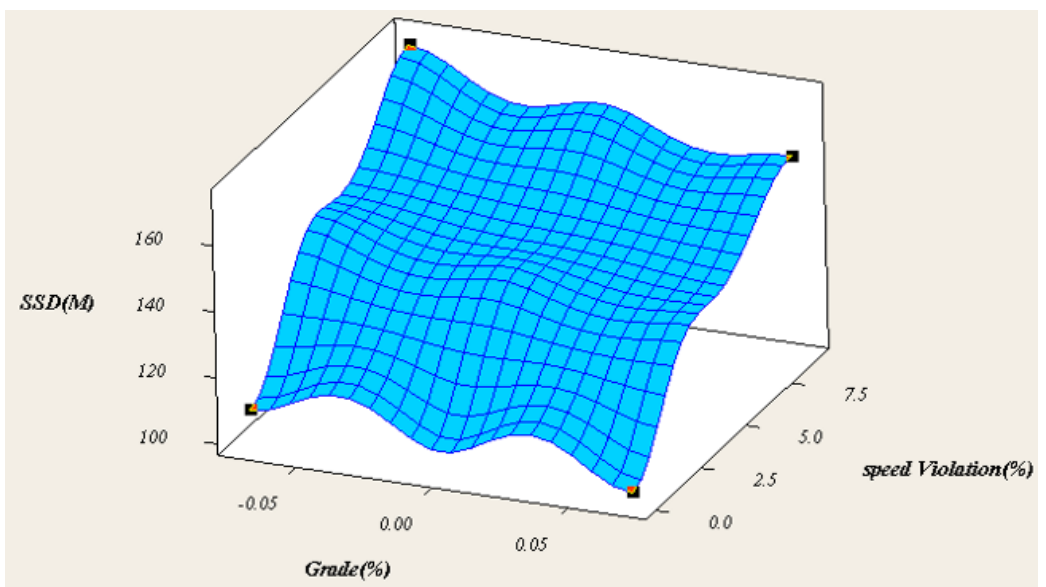

Health in

Emergencies and D] isasters [Oluarterly

Figure 4. The friction variation effect on the stopping distance in different longitudinal slopes 


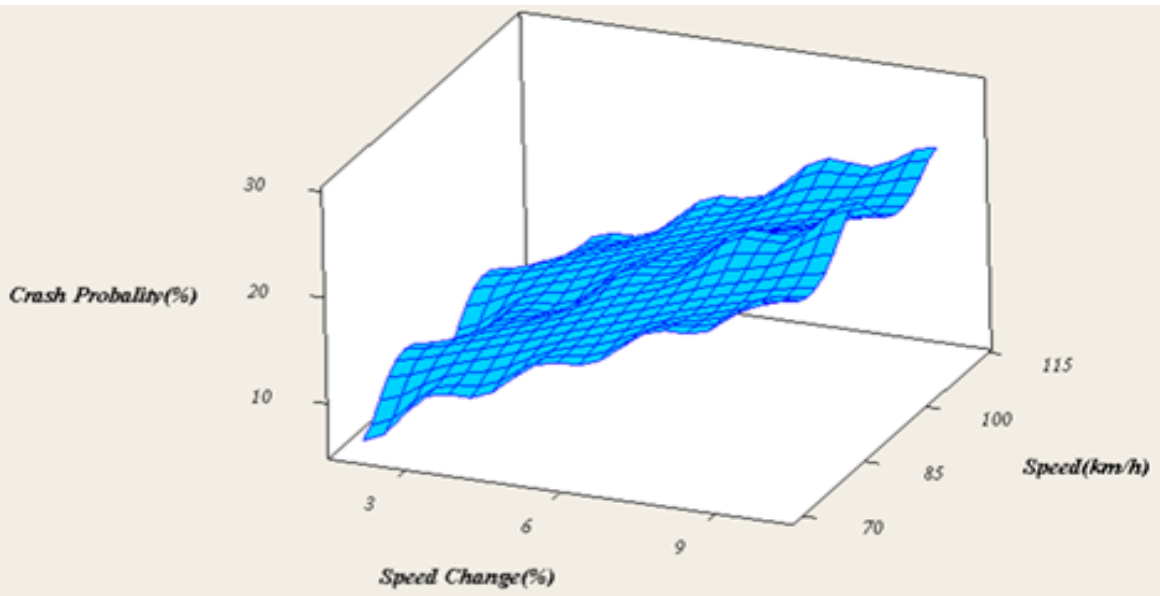

Figure 5. Comparison between the probabilities of a crash in the change of design speed

Emergencies and |D]isasters [Oluarterly

cal knowledge can define and recommend the priority of factors affecting optimal rescue vehicle speed as data clustering procedures.

According to the results of this research, to enhance the safety of the vertical curve, the outcomes should be con- sidered in the subsequent versions of the Geometric Design Regulations and standards. Moreover, the officials in Rescue and Relief Offices must take steps to reduce the original causes of the increase in accidents in the wet pavement in flood. Any accident is initiated by a viola-

Table 1. Samples of calculation of changes in speed and its result on driving events risk

\begin{tabular}{|c|c|c|c|c|}
\hline Design Speed (km/h) & Percentage of Speed Change (\%) & Increased Speed (km/h) & $\mathrm{LN}(\mathrm{m})$ & PA (\%)* \\
\hline & 2 & 71.5 & 115 & 6 \\
\hline & 4 & 72 & 122 & 11.5 \\
\hline \multirow[t]{5}{*}{$\begin{array}{l}70(\mathrm{~km} / \mathrm{h}) \\
\mathrm{LE}=108 \mathrm{~m}\end{array}$} & 6 & 74 & 129 & 16 \\
\hline & 8 & 75.5 & 136 & 20.5 \\
\hline & 10 & 77 & 144 & 25 \\
\hline & 2 & 91.8 & 271 & 7 \\
\hline & 4 & 93.5 & 290 & 13 \\
\hline \multirow[t]{5}{*}{$\begin{array}{l}90(\mathrm{~km} / \mathrm{h}) \\
\mathrm{LE}=252 \mathrm{~m}\end{array}$} & 6 & 95.5 & 308 & 18 \\
\hline & 8 & 97 & 327 & 23 \\
\hline & 10 & 99 & 346 & 27 \\
\hline & 2 & 112.2 & 516 & 7 \\
\hline & 4 & 114.5 & 552 & 13 \\
\hline \multirow[t]{3}{*}{$\begin{array}{l}110(\mathrm{~km} / \mathrm{h}) \\
\mathrm{LE}=480 \mathrm{~m}\end{array}$} & 6 & 116.5 & 588 & 18 \\
\hline & 8 & 119 & 624 & 23 \\
\hline & 10 & 120 & 644 & 25.5 \\
\hline
\end{tabular}

*PA: Risk of accident; LN: Need length of vertical curve considering the vehicle speed while passing; LE: Existing length of vertical curve considering design speed. 


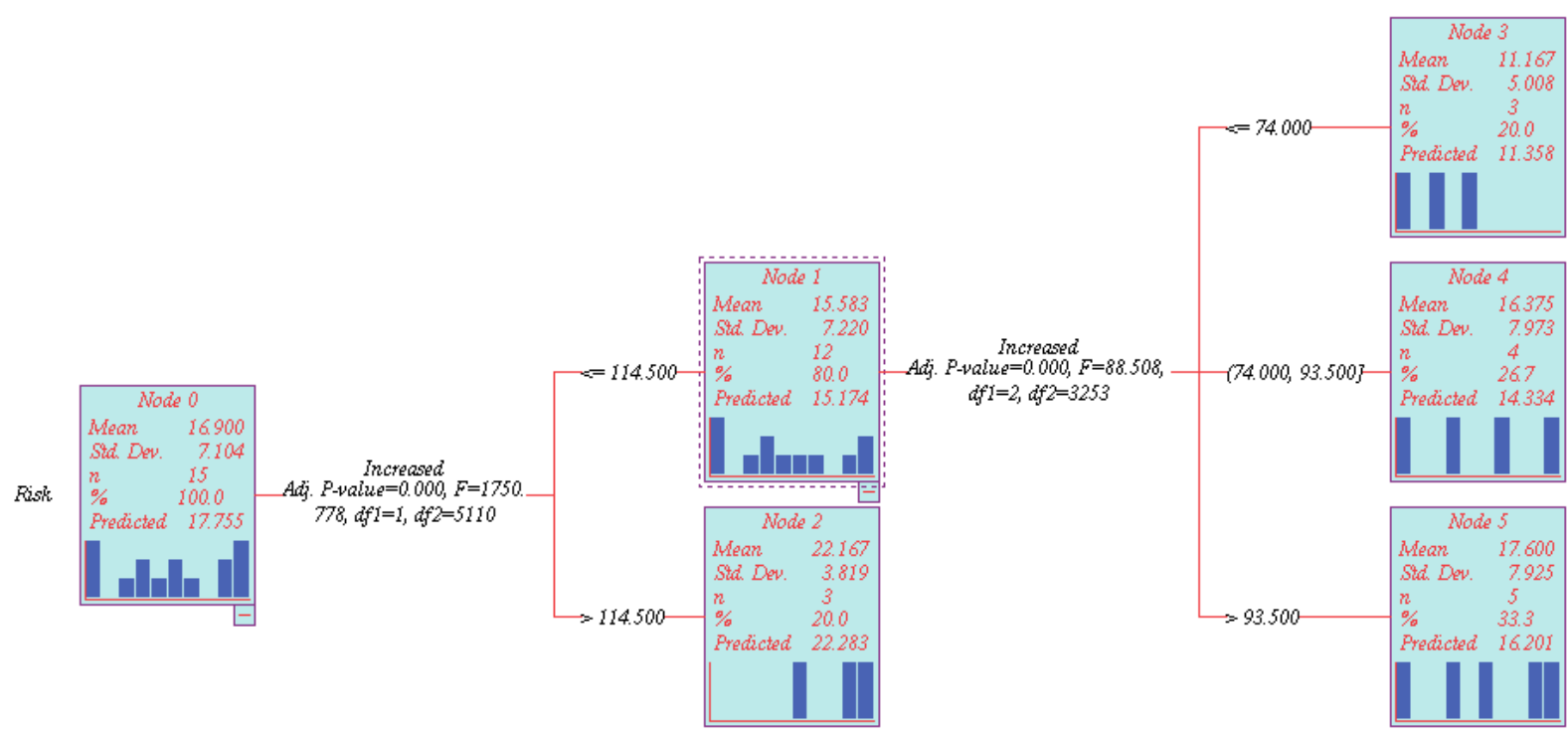

Figure 6. Decision tree pattern for predicting the rescue vehicles' driving accidents

tion of the traffic rule that occurs when the best pavement condition is ignored.

\section{Conclusion}

This study investigated the possibility of risk due to friction reduction in flood crises to increase the reliability of rescue vehicle drivers by emphasizing the statistical structure. Based on the calculation, modeling of risk conditions, and previous expressions and graphs, the results are summarized as follows:

1. The probability of crash increase by $2.5 \%$ on average for each $1 \%$ increase of speed in vertical crest curves. So, by a $10 \%$ increase in speed, the probability of driving events increases $25 \%$.

2. Increase of speed (violation and high-speed Rescue vehicles) over $90 \mathrm{~km} / \mathrm{h}$ extends the risk of a crash (2.7\%) by greater intensity. So, it is suggested to do more control in driving by speeds over $90 \mathrm{~km} / \mathrm{h}$.

3. Rate of change of grade in high speed (over $90 \mathrm{~km} / \mathrm{h}$ ) has a more significant effect on the required length of crest vertical curves. Therefore, $1 \%$ increase in " $A$ " in speed lower than $90 \mathrm{~km} / \mathrm{h}$ extends the required length of the curve about $25 \mathrm{~m}$. For speeds over $90 \mathrm{~km} / \mathrm{h}$, this length will be120 m, on average.

4. With a $5 \%$ reduction in surface friction in the wet pavement in flood, in other words, in the slippery road, the stop distance increases by $40 \%$. Since the vertical length of the curve is constant, the possibility of accidents will increase.

5. Considering the cost of earthwork for providing the length of crest vertical curves, it is suggested that in the sharp vertical curves (high rate of change of grade), the design speed decreases to lower than $90 \mathrm{~km} / \mathrm{h}$.

6 . The decision tree pattern results indicate that rescue vehicle speed has the most important effect on rescue vehicles' driving accident risk.

\section{Ethical Considerations}

\section{Compliance with ethical guidelines}

There were no ethical considerations to be considered in this research.

\section{Funding}

This research did not receive any grant from funding agencies in the public, commercial, or non-profit sectors.

\section{Authors' contributions}

Methodology, investigation, and writing - original draft: Mohammad Mehdi Khabiri; Writing - review \& editing: Zohrah Ghaforifard.

\section{Conflict of interest}

The authors declared no conflict of interest. 


\section{Acknowledgments}

We would like to appreciate S. Bazgir for his constructive suggestions for planning of this research. We also thank the staff of the Central Library of Yazd University for helping us in data collection.

\section{Referencecs}

[1] Fagnant DJ, Kockelman K. Preparing a nation for autonomous vehicles: Opportunities, barriers and policy recommendations. Transportation Research Part A: Policy and Practice. 2015; 77:167-81. [DOI:10.1016/j.ssci.2015.06.016.]

[2] Pratt RI, Roush NH, Ruff WT, Schneider ME, Weingartz J. American Association of State Highway and Transportation Officials. Washington, D.C.: Committee Correspondence; 2000. http://sp.design.transportation.org/Documents/TFPEMFall00.pdf

[3] Parkin J, Koorey G. Network planning and infrastructure design. In: Parkin J, editors. Cycling and Sustainability (Transport and Sustainability). Bingley: Emerald Group Publishing; 2012. [DOI:10.1108/S2044-9941(2012)0000001008]

[4] Lee S. Analysis of design elements for urban highway safety. Paper presented at: $4^{\text {th }}$ IRTAD Conference. 16-17 September 2009; Korea: Seoul. https://journals.sagepub.com/doi/ abs/10.3141/2195-07

[5] Ziari H, Khabiri MM. Analysis characteristics and provide a prediction model of public bus accident in Tehran. Journal of Applied Sciences. 2006; 6(2):247-50. [DOI:10.3923/ jas.2006.247.250]

[6] Omidi MR, Jafari Eskandari M, Raissi S, Shojaei AA. Providing an appropriate prediction model for traffic accidents: A case study on accidents in Golestan, Mazandaran, Guilan, and Ardebil Provinces. Health in Emergencies and Disasters. 2019; 4(3):165-72. [DOI:10.32598/hdq.4.3.165]

[7] Renski H, Khattak AJ, Council FM. Effect of speed limit increases on crash injury severity: Analysis of single-vehicle crashes on North Carolina interstate highways. Transportation Research Record. 1999; 1665(1):100-8. [DOI:10.3141/1665-14]

[8] Moomen M, Rezapour M, Raja MN, Ksaibati K. Predicting injury severity and crash frequency: Insights into the impacts of geometric variables on downgrade crashes in Wyoming. Journal of Traffic and Transportation Engineering (English edition). 2020; 7(3):375-83. [DOI:10.1016/j.jtte.2019.04.002]

[9] Hong SJ, Oguchi T. Evaluation of highway geometric design and analysis of actual operating speed. Journal of the Eastern Asia Society for Transportation Studies. 2005; 6:1048-61. [DOI:10.11175/easts.6.1048]

[10] Prassas ES, Roess RP. The Highway Capacity Manual: A conceptual and research history. New York: Springer; 2020. [DOI:10.1007/978-3-030-34480-1_1]

[11] Carsky J, Johanidesova A, Kocourek J. Findings of the safety inspections found on the TEN-T road network in the
Czech Republic. International Journal of Integrated Engineering. 2018; 10(2). [DOI:10.30880/ijie.2018.10.02.010]

[12] Sheikhbardsiri $H$, Yarmohammadian MH, Khankeh $H$, Khademipour G, Moradian MJ, Rastegarfar B, et al. An operational exercise for disaster assessment and emergency preparedness in south of Iran. Journal of Public Health Management and Practice. 2020; 26(5):451-6. [DOI:10.1097/ PHH.0000000000000815] [PMID]

[13] Chaithoo DB, Allopi D. Re-evaluating superelevation in relation to drainage requirements and vehicle dynamics. WIT Transactions on The Built Environment. 2012; 128:615-28. [DOI:10.2495/UT120521]

[14] Mavromatis S, Matragos V, Papantoniou P. Crest vertical curvature safety assessment through variable grade stopping sight distance control. Transportation Research Procedia. 2020; 45:426-33. [DOI:10.1016/j.trpro.2020.03.035]

[15] Dong C, Nambisan SS, Richards SH, Ma Z. Assessment of the effects of highway geometric design features on the frequency of truck involved crashes using bivariate regression. Transportation Research Part A: Policy and Practice. 2015; 75:30-41. [DOI:10.1016/j.tra.2015.03.007.]

[16] Aboutalebi Esfahani M, Hojjati SM. Evaluation of horizontal curve radius in overlap with longitudinal slope and vertical curve. Transportation Letters. 2020;1-0. [DOI:10.1080/194 27867.2020.1720105]

[17] Easa SM, Mehmood A. Establishing highway horizontal alignment to maximize design consistency. Canadian Journal of Civil Engineering. 2007; 34(9):1159-68. [DOI:10.1139/ 107-043]

[18] Aarts L, Van Schagen I. Driving speed and the risk of road crashes: A review. Accident Analysis \& Prevention. 2006; 38(2):215-24. [DOI:10.1016/j.aap.2005.07.004] [PMID]

[19] Lord D, Bonneson JA. Role and application of accident modification factors within highway design process. Transportation Research Record. 2006; 1961(1):65-73. [DOI:10.1177 /0361198106196100108]

[20] Šliupas T. The impact of road parameters and the surrounding area on traffic accidents. Transport. 2009; 24(1):42-7. [DOI:10.3846/1648-4142.2009.24.42-47]

[21] Prentkovskis O, Beljatynskij A, Prentkovskiene R, Dyakov I, Dabulevičiene L. A study of the deflections of metal road guardrail elements. Transport. 2009; 24(3):225-33. [DOI:10.3846/1648-4142.2009.24.225-233]

[22] MiaouSP, Lum H. Modeling vehicle accidents and highway geometric design relationships. Accident Analysis \& Prevention. 1993; 25(6):689-709. [DOI:10.1016/0001-4575(93)90034-T] 
This Page Intentionally Left Blank 